\title{
A new coupling reaction for the synthesis of ruthenium half-sandwich complexes with sterically demanding cyclopentadienyl ligands $\uparrow$
}

\author{
Sébastien Gauthier, Euro Solari, Barnali Dutta, Rosario Scopelliti and Kay Severin* \\ Received (in Cambridge, UK) 22nd December 2006, Accepted 19th January 2007 \\ First published as an Advance Article on the web 9th February 2007 \\ DOI: $10.1039 / b 618712 a$
}

The reaction of $\mathrm{RuCl}_{3}(\mathrm{solv} .)_{n}$ with tert-butylacetylene in methanol or ethanol leads to the formation of chloro-bridged half-sandwich complexes with sterically demanding cyclopentadienyl ligands, which are of high interest as starting materials for the synthesis of novel Ru catalysts.

Ruthenium half-sandwich complexes with cyclopentadienyl ligands constitute a very important class of catalysts. ${ }^{1}$ The transformations catalyzed by these complexes include allylic ${ }^{2}$ and propargylic ${ }^{3}$ substitutions, cycloadditions, ${ }^{4}$ isomerizations, ${ }^{5}$ alkane borylations, ${ }^{6}$ and atom transfer radical addition ${ }^{7}$ and polymerization $^{8}$ reactions, among many others. ${ }^{1}$ In order to optimize the catalytic performance for a given reaction, a plethora of co-ligands have been employed, such as phosphines, olefins, halides, nitriles and thiolates. Structural modifications of the cyclopentadienyl ligand, on the other hand, are not very common, and most investigations have focused on $\mathrm{Cp}$ and $\mathrm{Cp}^{*}$ complexes.t The likely explanation for the dominance of $\mathrm{Cp}$ and $\mathrm{Cp}^{*}$ ligands is the fact that versatile and easily accessible starting materials are available for these complexes. The cationic acetonitrile complex $\left[\left\{\mathrm{CpRu}\left(\mathrm{CH}_{3} \mathrm{CN}\right)_{3}\right\}\left(\mathrm{PF}_{6}\right)\right]$ (1) and chloro-bridged dimer $\left[\mathrm{Cp}^{*} \mathrm{RuCl}_{2}\right]_{2}$ (2) have turned out to be particularly useful. The latter can be obtained in a one-step procedure from $\left[\mathrm{RuCl}_{3}\left(\mathrm{H}_{2} \mathrm{O}\right)_{n}\right],{ }^{9}$ and convenient syntheses have been developed for the former. ${ }^{10}$ Meanwhile, both complexes are also commercially available.

In the following communication, we describe a simple procedure for the synthesis of two dimeric $\mathrm{Ru}^{\mathrm{III}}$ complexes, $\mathbf{3}$ and $\mathbf{4}$, which show overall structures analogous to 2 , but have very distinctive cyclopentadienyl ligands. These complexes are obtained from $\left.\left[\mathrm{RuCl}_{3} \text { (solv. }\right)_{n}\right]$ in an unprecedented Ru-mediated coupling reaction of three alkynes and an alcohol. They are expected to become useful starting materials for the synthesis of novel Ru catalysts, as evidenced by a first application in a racemization reaction.

When a solution of $\left.\left[\mathrm{RuCl}_{3} \text { (solv. }\right)_{n}\right] \S$ and 4.2 equivalents of tertbutylacetylene in methanol were heated to $55^{\circ} \mathrm{C}$, a brown powder began to precipitate after $2 \mathrm{~h}$ (Scheme 1). After $24 \mathrm{~h}$, the mixture was cooled to $-20{ }^{\circ} \mathrm{C}$ and complex 3 was isolated in $51 \%$ yield (see ESI $\dagger$ )

Elemental analysis of complex 3 showed that a carbon-rich compound had formed $(\mathrm{C}=50.47 \%)$. Attempts to obtain further

Institut des Sciences et Ingénierie Chimiques, École Polytechnique Fédérale de Lausanne (EPFL), Lausanne, Switzerland. E-mail: kay.severin@epfl.ch; Fax:+41(0)216939305, Tel: +41 (0)216939302

$\uparrow$ Electronic supplementary information (ESI) available: Experimental details. See DOI: $10.1039 / \mathrm{b} 618712 \mathrm{a}$

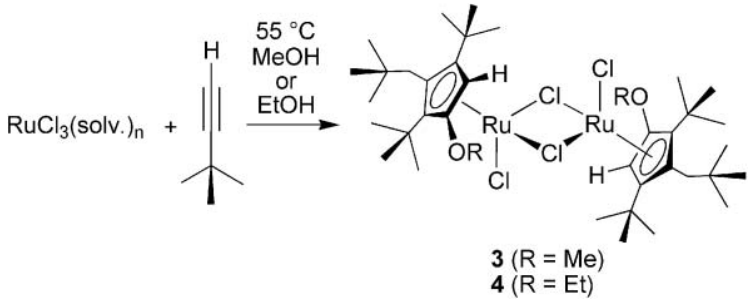

Scheme 1 Synthesis of the complexes 3 and $\mathbf{4}$.

structural information by NMR spectroscopy were not successful, indicating the presence of paramagnetic $\mathrm{Ru}^{\mathrm{III}}$. This was confirmed by a single crystal X-ray analysis. The overall structure of complex $\mathbf{3}$ is similar to that of $\mathbf{2}$ : two $\left(\eta^{5}\right.$-cyclopentadienyl) $\mathrm{RuCl}_{2}$ fragments are connected by two chloro bridges to form a centrosymmetric dimer (Fig. 1). However, the cyclopentadienyl ligands show a unique substitution pattern, with two tert-butyl, one neopentyl and one methoxy group attached to the aromatic ring. Due to the presence of different side chains, the ( $\pi$-ligand $) \mathrm{Ru}$ fragment displays planar chirality. There are two independent ( $\pi$-ligand) $\mathrm{RuCl}_{2}$ complexes in the asymmetric unit; the dimers are obtained by the symmetry operation $-x, 1-y, z$ and $1-x, 1-y$, $1-z$, respectively. The $\mathrm{Ru}$ atoms in these dimers are 3.684(1) and 3.743(1) $\AA$ apart from each other, and therefore not bonded to each other. ${ }^{11}$

When $\left[\mathrm{RuCl}_{3}(\text { solv. })_{n}\right]$ was reacted with tert-butylacetylene in ethanol instead of methanol, the ethoxy complex $\mathbf{4}$ was obtained in $40 \%$ yield (see ESI $\dagger$ ). The structure of $\mathbf{4}$ is analogous to that of

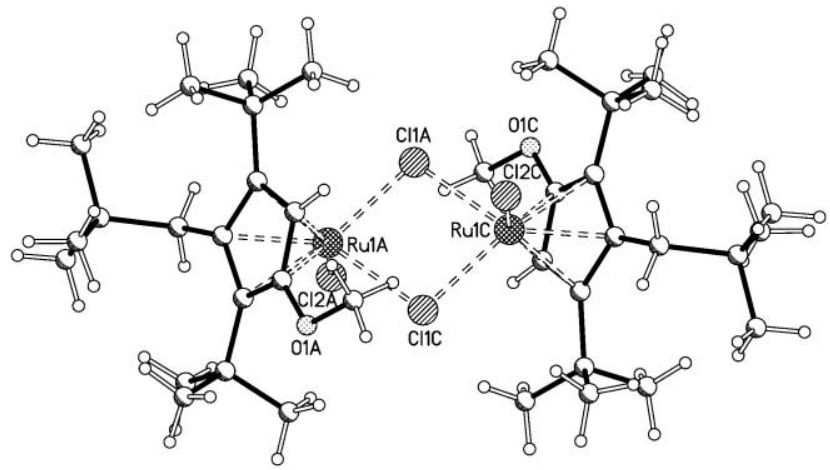

Fig. 1 Graphical representation of the molecular structure of complex 3 in the crystal. Selected bond lengths $[\AA]$ and angles [ [ ]: RulA-Cl1A

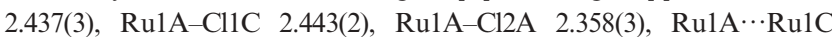
3.684(1); Cl1A-Ru1A-Cl2A 88.89(10), Cl1A-Ru1A-Cl1C 99.0(3). Only one of the two independent dimers is shown. The letter $\mathrm{C}$ stands for the symmetry operation: $-x, 1-y,-z$. 
complex $\mathbf{3}$, as evidenced by elemental analysis and by subsequent reduction to diamagnetic complexes, which can be analyzed by NMR spectroscopy (see below).

The formation of complexes $\mathbf{3}$ and $\mathbf{4}$ can be explained by a Rumediated coupling reaction of three tert-butylacetylenes with methanol or ethanol and with the elimination of $\mathrm{HCl}$. Transition metal-mediated $[2+2+1]$ cyclotrimerizations of alkynes have been observed in some cases, ${ }^{12,13}$ but they are very rare compared to the more common $[2+2+2]$ cyclotrimerizations. ${ }^{1,4}$ A coupling reaction of three alkynes and an alcohol, giving a cyclopentadienyl ligand with an alkoxy-substituent directly attached to the ring, is, to best of our knowledge, unprecedented. The five-membered ring might be formed by an intramolecular reaction of a metallacyclopentadiene with a vinylidene ligand, as described for other systems. ${ }^{12 a}$ Fulvene $\pi$-complexes have been suggested as intermediates in the $[2+2+1]$ cyclotrimerization of alkynes. In our case, such an intermediate seems unlikely because the nucleophilic attack of an alcohol would be expected to occur at the exocyclic carbon atom. $^{13}$

When phenylacetylene, cyclohexylacetylene or trimethylsilylacetylene were used instead of tert-butylacetylene, a mixture of unidentified products was obtained. The difficulty in obtaining coupling products analogous to $\mathbf{3}$ and $\mathbf{4}$ with other alkynes was not unexpected. A complicated multi-component reaction of this kind is likely to depend strongly on the size and reactivity of the alkyne. Furthermore, it is known that (cyclopentadienyl)Ru half-sandwich complexes (including dimer 2) ${ }^{14}$ can react further with alkynes to give cycloaddition products or polymers. ${ }^{1,4}$ The importance of such consecutive reactions will again depend on the nature of the alkyne. Nevertheless, it is conceivable that complexes of type $\mathbf{3}$ and 4 can be obtained for other alkyne/alcohol combinations if a careful optimization of the reaction conditions is carried out.

First investigations showed that complexes $\mathbf{3}$ and $\mathbf{4}$ could be easily transformed into diamagnetic $\mathrm{Ru}^{\mathrm{II}}$ complexes with various co-ligands (see ESI $\dagger$ ). The reaction of 3 with norbornadiene (NBD) in EtOH at $55{ }^{\circ} \mathrm{C}$ gave complex 5 in $60 \%$ yield (Scheme 2). The accessibility of $\mathbf{5}$ is of interest in view of the fact that the analogous $\mathrm{Cp}^{*}$ complexes $\left[\mathrm{Cp}^{*} \mathrm{RuCl}(\mathrm{NBD})\right]$ and $[\mathrm{Cp} * \mathrm{RuCl}(\mathrm{COD})]$ have been used extensively as catalysts for various organic transformations. ${ }^{1}$

When 3 was reacted with $\mathrm{PCy}_{3}$ or $\mathrm{PPh}_{3}$ in THF in the presence of $\mathrm{Zn}$, deep purple solutions were obtained, from which the $16 \mathrm{e}^{-}$ complexes 6 and 7 were isolated. Apart from NMR spectroscopy and elemental analysis (see ESI $\dagger$ ), complex 7 was characterized by single-crystal X-ray analysis (Fig. 2). I It is interesting to note that structurally related $\mathrm{Cp}^{*} \mathrm{Ru}^{\mathrm{II}}$ complexes have been isolated with sterically demanding phosphine ligands such as $\mathrm{PCy}_{3}$ and $\mathrm{P} \mathrm{Pr}_{3}$, but not with $\mathrm{PPh}_{3}$. ${ }^{15}$ On the contrary, attempts to make mononuclear $\left[\mathrm{Cp} * \mathrm{RuCl}\left(\mathrm{PPh}_{3}\right)\right]$ failed and gave instead an insoluble material, which was suggested to have a polymeric structure. ${ }^{16}$ This demonstrates that the sterically very demanding 2,4-bis-tert-butyl-1-methoxy-3-neopentylcyclopentadienyl ligand is able to stabilize complexes that are not accessible with the standard $\mathrm{Cp} *$ ligand.

The synthesis of the $\mathrm{Ru}^{\mathrm{II}}$-carbonyl complexes $\mathbf{8}$ and $\mathbf{9}$ was accomplished by the carbonylation (1 bar, RT) of cationic tris(acetonitrile) complexes, which were prepared in situ by reduction of $\mathbf{3}$ or $\mathbf{4}$ with $\mathrm{Zn}$ (Scheme 2). ${ }^{17}$ The air stable CO complexes $\mathbf{8}$ and $\mathbf{9}$ were obtained in good yield after purification

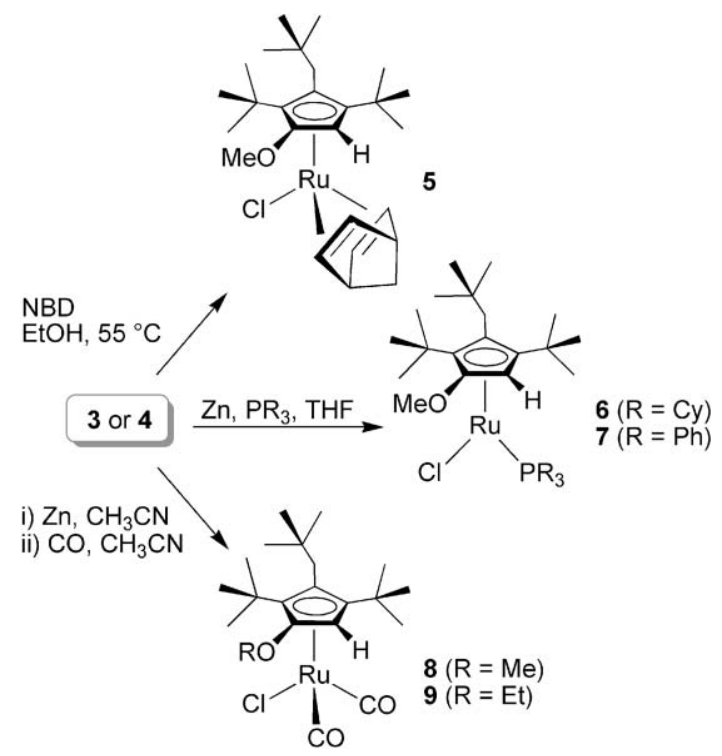

Scheme 2 Dimers 3 and $\mathbf{4}$ are versatile starting materials for the synthesis of diamagnetic $\mathrm{Ru}^{\mathrm{II}}$ complexes with sterically demanding cyclopentadienyl ligands. For each product, only one of the two enantiomers is shown.

by flash chromatography (see ESI $\dagger$ ). Compounds of this kind are of interest because (cyclopentadienyl) $\mathrm{Ru}(\mathrm{CO})_{2} \mathrm{X}$ complexes are frequently used as robust catalysts for the racemization of secondary alcohols. ${ }^{18}$ It had been reported that the substituents on the cyclopentadienyl ligand are of importance for the racemization reaction. ${ }^{18,19}$ This finding was the motivation to test the catalytic activity of our new complexes $\mathbf{8}$ and $\mathbf{9}$.

The racemization of $(S)$-1-phenylethanol was examined using $0.25 \mathrm{~mol} \%$ of complex 8 and $\mathbf{9}$, respectively. The reactions were performed without a protective inert atmosphere, and $\mathrm{K}_{3} \mathrm{PO}_{4}$ was used as a basic additive. Both complexes turned out to be highly active catalysts, with the methoxy complex $\mathbf{8}$ (complete racemization after $1 \mathrm{~h}$ ) being slightly more active than the ethoxy complex 9 (complete racemization after $1.5 \mathrm{~h}$ ). Other secondary alcohols such as (S)-4-phenyl-2-butanol, (S)-1-(2-naphthyl)ethanol and (S)-1indanol were also racemized within $1.0-1.5 \mathrm{~h}$ using $0.5 \mathrm{~mol} \%$ of

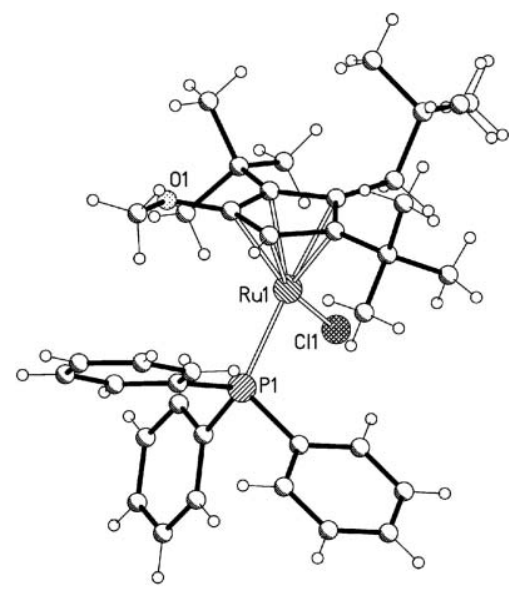

Fig. 2 Graphic representation of the molecular structure of complex 7 in the crystal. Selected bond lengths $[\AA]$ and angles [ $\left.{ }^{\circ}\right]$ : Rul-Cl1 2.3705(8), Ru1-P1 2.3786(9); Cl1-Ru1-P1 92.93(3). 
complex 8 (see ESI $\dagger$ ). These values are comparable to those reported for the most active Ru-catalysts described so far. ${ }^{18,19}$

In summary, we have described the syntheses and structures of chloro-bridged half-sandwich complexes 3 and 4. They were obtained in a single step by a new type of coupling reaction using $\left.\left[\mathrm{RuCl}_{3} \text { (solv. }\right)_{n}\right]$, tert-butylacetylene and methanol or ethanol. The complexes are expected to find high interest as starting materials for the synthesis of novel Ru catalysts. The basic structure of $\mathbf{3}$ and $\mathbf{4}$ are similar to that of complex $\mathbf{2}$, which represents one of the key entry points for the synthesis of (cyclopentadienyl)Ru catalysts. The $\pi$-ligands of $\mathbf{3}$ and $\mathbf{4}$, on the other hand, are quite different from $\mathrm{Cp}^{*}$ because of the sterically demanding tert-butyl and neopentyl groups, and the alkoxy substituent. This is evidenced by the synthesis of 7 , a $16 \mathrm{e}^{-}$complex which is not accessible with the standard $\mathrm{Cp}^{*}$ ligand. The facile transformation into mononuclear $\mathrm{Ru}^{\mathrm{II}}$ complexes and the application of $\mathbf{8}$ and $\mathbf{9}$ as highly efficient racemization catalysts under mild conditions represents further evidence for the utility of $\mathbf{3}$ and $\mathbf{4}$.

\section{Notes and references}

$\$ \eta^{5}$-Indenyl and tris(pyrazolyl)borate ligands have shown considerable success as substitutes for $\mathrm{Cp}$ and $\mathrm{Cp}$ * ligands (see refs. 1-8).

$\S$ An excess of water was found to reduce the overall yield. Prior to the reaction, the commercial $\left[\mathrm{RuCl}_{3}\left(\mathrm{H}_{2} \mathrm{O}\right)_{n}\right]$ was therefore treated with THF, as detailed in the ESI. $\dagger$

- Crystal data for complex 3: $\mathrm{C}_{38} \mathrm{H}_{66} \mathrm{Cl}_{4} \mathrm{O}_{2} \mathrm{Ru}_{2}, M_{\mathrm{r}}=898.85$, monoclinic, space group $P 2_{1} / c, a=23.624(2), b=14.0305(10), c=12.2973(8) \AA, \beta=$ $90.572(6)^{\circ}, V=4075.8(5) \AA^{3}, Z=4, \rho_{\text {calc }}=1.465 \mathrm{~g} \mathrm{~cm}^{-3}, \mu=1.034 \mathrm{~mm}^{-1}$, $F(000)=1864$, crystal dimensions $0.24 \times 0.20 \times 0.14 \mathrm{~mm}, T=140(2) \mathrm{K}$, Mo- $\mathrm{K}_{\alpha}$ radiation, $\lambda=0.71073 \AA, \theta=2.59-25.03^{\circ},-28 \leqslant h \leqslant 28,-13 \leqslant$ $k \leqslant 16,-14 \leqslant l \leqslant 14,23827$ reflections collected, 7185 independent reflections, $R_{\text {int }}=0.0751, R_{1}[I>2 \sigma(I)]=0.0586, \mathrm{w} R_{2}$ (all data) $=0.1557$, largest difference peak 1.199 e $\AA^{-3}$, largest difference minimum $-0.987 \mathrm{e} \AA^{-3}$. CCDC 609454. Crystal data for complex 7: $\mathrm{C}_{37} \mathrm{H}_{48} \mathrm{ClOPRu}, M_{\mathrm{r}}=676.24$, monoclinic, space group $P 2{ }_{1} / c, a=$ 17.879(3), $b=9.4034(7), c=20.2160(16) \AA, \quad \beta=92.158(8)^{\circ}, \quad V=$ $3396.3(6) \AA^{3}, Z=4, \rho_{\text {calc }}=1.323 \mathrm{~g} \mathrm{~cm}^{-3}, \mu=0.614 \mathrm{~mm}^{-1}, F(000)=1416$, crystal dimensions $0.61 \times 0.34 \times 0.15 \mathrm{~mm}, T=100(2) \mathrm{K}, \mathrm{Mo}-\mathrm{K}_{\alpha}$ radiation, $\lambda=0.71073 \AA, \theta=3.10-25.03^{\circ},-21 \leqslant h \leqslant 21,-11 \leqslant k \leqslant 11$, $-24 \leqslant l \leqslant 23,60255$ reflections collected, 5984 independent reflections, $R_{\text {int }}=0.0744, R_{1}[I>2 \sigma(I)]=0.0361, \mathrm{w} R_{2}$ (all data) $=0.0814$, largest difference peak 0.581 e $\AA^{-3}$, largest difference minimum -0.686 e $\AA^{-3}$. CCDC 631864. For crystallographic data in CIF or other electronic format see DOI: $10.1039 / \mathrm{b} 618712 \mathrm{a}$

1 (a) B. N. Trost, M. U. Frederiksen and M. T. Rudd, Angew. Chem., Int. Ed. 2005, 44, 6630; (b) S.-I. Murahashi, Ruthenium in Organic Synthesis, Wiley-VCH, Weinheim, 2004; (c) C. Bruneau and P. H. Dixneuf, Ruthenium Catalysts and Fine Chemistry, Springer, Berlin, 2004; (d) S. Dérien and P. H. Dixneuf, J. Organomet. Chem., 2004, 689, 1382; (e) B. M. Trost, F. D. Toste and A. B. Pinkerton, Chem. Rev., 2001, 101, 2067; (f) T. Naota, H. Takaya and S.-I. Murahashi, Chem. Rev., 1998, 98, 2599.

2 (a) C. Bruneau, J.-L. Renaud and B. Demerseman, Chem.-Eur. J., 2006, 12, 5178; (b) J.-L. Renaud, B. Demerseman, M. D. Mbaye and C. Bruneau, Curr. Org. Chem., 2006, 10, 115; (c) T. Kondo and T.-A. Mitsudo, Curr. Org. Chem., 2002, 6, 1163.

3 Y. Nishibayashi and S. Uemura, Curr. Org. Chem., 2006, 10, 135.

4 Y. Yamamoto and K. Itoh, "Carbon-Carbon Bond Formations via Ruthenacycle Intermediates", in Ruthenium in Organic Synthesis, ed. S.-I. Murahashi, Wiley-VCH, Weinheim, 2004, pp. 95.
5 H. Suzuki and T. Takao, "Isomerization of Organic Substrates Catalyzed by Ruthenium Complexes", in Ruthenium in Organic Synthesis, ed. S.-I. Murahashi, Wiley-VCH, Weinheim, 2004. pp. 309.

6 J. M. Murphy, J. D. Lawrence, K. Kawamura, C. Incarvito and J. F. Hartwig, J. Am. Chem. Soc., 2006, 128, 13684.

7 (a) K. Severin, Curr. Org. Chem., 2006, 10, 217; (b) L. Delaude, A. Demonceau and A. F. Noels, Top. Organomet. Chem., 2004, 11, 155.

8 (a) M. Kamigaito, T. Ando and M. Sawamoto, Chem. Rec., 2004, 4, 159; (b) M. Kamigaito, T. Ando and M. Sawamoto, Chem. Rev., 2001, $101,3689$.

9 (a) U. Kölle, J. Kossakowski, D. Grumbine and T. D. Tilley, Inorg. Synth., 1992, 29, 225; (b) T. D. Tilley, R. H. Grubbs and J. E. Bercaw, Organometallics, 1984, 3, 274; (c) N. Oshima, H. Suzuki and Y. Morooka, Chem. Lett., 1984, 1161.

10 (a) E. P. Kündig and F. R. Monnier, Adv. Synth. Catal., 2004, 346, 901; (b) B. M. Trost and C. M. Older, Organometallics, 2002, 21, 2544; (c) T. P. Gilla and K. R. Mann, Organometallics, 1982, 1, 485.

11 For a discussion about metal-metal interactions in dimer 2, see: (a) J. E. McGrady, Angew. Chem., Int. Ed., 2000, 39, 3077; (b) U. Kölle, K. Lueken, K. Handrick, H. Schilder, J. K. Burdett and S. Balleza, Inorg. Chem., 1995, 34, 6273; (c) U. Kölle, J. Kossakowski, N. Klaff, L. Wesemann, U. Englert and G. E. Heberich, Angew. Chem., Int. Ed. Engl., 1991, 30, 690.

12 (a) C. S. Chin and H. Lee, Chem.-Eur. J., 2004, 10, 4518; (b) E. Becker, K. Mereitner, M. Puchberger, R. Schmid, K. Kirchner, A. Doppiu and A. Salzer, Organometallics, 2003, 22, 3164; (c) U. Radhakrishnan, V. Gevorgyan and Y. Yamamoto, Tetrahedron Lett., 2000, 41, 1971; (d) H.-J. Kim, N.-S. Choi and S. W. Lee, J. Organomet. Chem., 2000, 616, 67; (e) A. D. Burrows, M. Green, J. C. Jeffery, J. M. Lynam and M. F. Mahon, Angew. Chem., Int. Ed., 1999, 38, 3043; (f) E. S. Johnson, G. J. Balaich, P. E. Fanwick and I. P. Rothwell, J. Am. Chem. Soc., 1997, 119, 11086; ( $g$ ) J. M. O’Connor, K. Hiibner, R. Merwin, P. K. Gantzel and B. S. Fong, J. Am. Chem. Soc., 1997, 119, 3631; $(h)$ G. Moran, M. Green and A. G. Orpen, J. Organomet. Chem., 1983, 250, $\mathrm{C} 15$.

13 (a) M. S. Lim, J. Y. Baeg and S. W. Lee, J. Organomet. Chem., 2006, 691, 4100; (b) W. S. Han and S. W. Lee, Organometallics, 2005, 24, 997.

14 For the reaction of complex 2 with alkynes, see: (a) T. Fukuyama, R. Yamaura, Y. Higashibeppu, T. Okamura, I. Ryu, T. Kondo and T.-A. Mitsudo, Org. Lett., 2005, 7, 5781; (b) I. Yamaguchi, K. Osakada and T. Yamamoto, Inorg. Chim. Acta, 1994, 220, 35.

15 (a) J. Huang, E. D. Stevens, S. P. Nolan and J. L. Petersen, J. Am. Chem. Soc., 1999, 121, 2674; (b) J. Huang, E. D. Stevens, S. P. Nolan and J. L. Petersen, Organometallics, 1999, 121, 2674; (c) L. Luo and S. P. Nolan, Organometallics, 1994, 13, 4781; (d) T. J. Johnson, K. Folting, W. E. Streib, J. D. Martin, J. C. Huffman, S. A. Jackson, O. Eisenstein and K. G. Caulton, Inorg. Chem., 1995, 34, 488; (e) B. K. Campion, R. H. Heyn and T. D. Tilley, J. Chem. Soc., Chem. Commun., 1988, 278.

16 T. Braun, G. Münch, B. Windmüller, O. Gevert, M. Laubender and H. Werner, Chem.-Eur. J., 2003, 9, 2516.

17 For analogous reactions with complex 2, see: (a) B. Steinmetz and W. A. Schenk, Organometallics, 1999, 18, 943; (b) U. Kölle, B.-S. Kang and U. Englert, J. Organomet. Chem., 1991, 420, 227.

18 For reviews, see: (a) N. J. Turner, Curr. Opin. Chem. Biol, 2004, 8, 114; (b) O. Pàmies and J.-E. Bäckvall, Chem. Rev., 2003, 103, 3247; (c) H. Pellisier, Tetrahedron, 2003, 59, 8291; (d) M.-J. Kim, Y. Ahn and J. Park, Curr. Opin. Biotechnol., 2002, 13, 578.

19 For some highly active racemization catalysts, see: $(a)$ B. MartínMatute, M. Edin, K. Bogár, F. B. Kaynak and J.-E. Bäckvall, J. Am. Chem. Soc., 2005, 127, 8817; (b) N. Kim, S.-B. Ko, M. S. Kwon, M.-J. Kim and J. Park, Org. Lett., 2005, 7, 4523; (c) J. H. Choi, Y. K. Choi, Y. H. Kim, E. S. Park, E. J. Kim, M.-J. Kim and J. Park, J. Org. Chem., 2004, 69, 1972; (d) B. Martín-Matute, M. Edin, K. Bogár and J.-E. Bäckvall, Angew. Chem., Int. Ed., 2004, 116, 6535; (e) M.-J. Kim, Y. I. Chung, Y. K. Choi, H. K. Lee, D. Kim and J. Park, J. Am. Chem. Soc., 2003, 125, 11494; (f) J. H. Choi, Y. H. Kim, S. H. Nam, S. T. Shin, M.-J. Kim and J. Park, Angew. Chem., Int. Ed., 2002, 114, 2373. 